\title{
Industrial Policy to Develop a Multi-Firm Industry
}

\author{
Tigran Melkonyan ${ }^{1} \cdot$ Dwayne Banks $^{2} \cdot{\text { Jeanne } \text { Wendel }^{3}}^{3}$
}

Received: 11 August 2016/Revised: 27 November 2016 /

Accepted: 21 December 2016/Published online: 23 January 2017

(C) The Author(s) 2017. This article is published with open access at Springerlink.com

\begin{abstract}
Governments face pressure to act when coordination and learning externalities block development of otherwise-profitable industries that would produce merit goods for the domestic market. A short-term subsidy that offsets these externalities could potentially jumpstart a multi-firm industry, if the subsidy induces a pioneer firm to enter and then the pioneer's first-period output generates coordination and learning externalities. These externalities could induce subsequent entry by input suppliers and/or competitors. However, empirical evidence raises questions about the ability of governments to use short-term subsidies to jump-start new industries. We explore one explanation for the difficulty of jump-starting new industries: the subsidy could generate counter-productive incentives for the pioneer firm to prevent entry of additional firms. We model the jump-start strategy and examine whether coupling a short-term fixed subsidy with a per-unit subsidy can achieve the objective of creating a multi-firm industry.
\end{abstract}

Keywords Jump-starting a multi-firm industry $\cdot$ Entry promotion $\cdot$ Entry deterrence $\cdot$ Subsidy

JEL classification $\mathrm{H} 2 \cdot \mathrm{L} 1 \cdot \mathrm{L} 5$

Tigran Melkonyan

Tigran.Melkonyan@wbs.ac.uk

Dwayne Banks

sbdean@ollusa.edu

Jeanne Wendel

wendel@unr.edu

1 Warwick Business School, University of Warwick, Scarman Road, Coventry CV47AL, UK

2 Our Lady of the Lake University of San Antonio, San Antonio, USA

3 Department of Economics, University of Nevada, Reno 89557, USA 


\section{Introduction}

Learning externalities and coordination failures can create stalemates that block the development of otherwise profitable industries, if pioneer entrants incur first-mover costs to develop new production or distribution methods, organize new supply networks, or educate potential customers about a new product, while subsequent entrants enjoy external benefits generated by the pioneer's efforts (Krugman 1987; Romero-Martínez and Montoro-Sánchez 2008). Potential entrants may respond to this first-mover disadvantage by waiting for their counterparts to enter first, and, as a result, potentially-profitable industries may not develop.

If the blocked industry would produce a merit good (such as electric cars, solar energy, electronic exchange of health information, fuel cell buses, or new types of healthcare in a developing country), advocacy groups may pressure the government to overcome this market failure. The political appeal of this position is enhanced by the presumption that the coordination and learning-externality market failures are short-term problems that can be addressed with a targeted short-term subsidy. This subsidy would be designed to induce initial entry, by compensating the pioneer for activities that generate learning externalities and obviate coordination failures. The resulting pioneer entry then creates the conditions that induce subsequent entry by additional firms. This strategy offers two attractive features:

- It limits government involvement in the industry to the initial stages of industry development, without enmeshing the government in an ongoing effort to influence the industry's evolution.

- It also allows the government to side-step the question of whether it can take on long-term financial commitments.

However, efforts to jump-start a merit-good industry face a tougher challenge than more traditional efforts to jump-start export-industries. Subsidy design for jump-starting an export industry can focus on inducing entry by a pioneer producer, followed by subsequent entry by complementary firms such as input suppliers. Subsidy design for jump-starting a domestic merit-good industry must accomplish this goal, while also inducing subsequent entry by competitive firms that will mitigate the initial market power enjoyed by the pioneer entrant.

Despite these challenges, the straightforward market-failure logic and the apparent simplicity of designing a short-term subsidy to ameliorate these market-failures have enticed governments to attempt jump-starting numerous industries. The Dubai Health Care City (DHCC) provides a rich example, because large-scale pioneer entry was expected to lead to lower operating costs for subsequent entrants that would deliver both competitive services and complementary services. DHCC was designed to provide high-quality healthcare in both the "export" medical tourism market and in the domestic healthcare market. Domestic availability of new types of high-quality healthcare was viewed as a merit good that would provide essential infrastructure to support efforts to induce foreign firms to relocate professional employees to Dubai. Providing a short-term subsidy to induce pioneer entry raised the question: is it possible to subsidize entry of a highquality hospital without creating a first-mover advantage that would deter subsequent entry by additional organizations? Due to coordination and learning market failures, the pioneer faced firstmover challenges: medical and nursing schools were not available to provide locally-trained personnel to staff the new hospital, local pharmaceutical and medical supply chains were not welldeveloped, and the network of local ancillary healthcare service-providers (such as nursing facilities) was not well-developed. These challenges implied that the pioneer would incur first- 
mover costs, and they also implied that construction and operation of a large-scale pioneer facility was likely to generate subsequent entry by medical and nursing schools, pharmaceutical and medical supply distribution companies, entities providing ancillary healthcare services. Development of these infrastructure industries could induce subsequent entry by additional hospitals that would compete with the pioneer. Thus, pioneer entry was expected to induce entry by complementary firms, and this entry was expected to reduce hospital operating costs. The resulting reduction in operating costs was expected to induce competitive entry by additional hospitals, if the short-term subsidies offered to the pioneer entrant could be crafted to offset the firm-mover costs, without creating a long-term first-mover advantage. Consistent with this logic, Harvard Medical School announced plans in 2015 to partner with entities in Dubai to open a high-quality medical school and research facility, and Cleveland Clinic Abu Dhabi was opened in 2015.

The desire to accomplish this goal is not unique to DHCC. The U.S. government has funded targeted subsidies for firms developing products to meet an array of social goals, including development and diffusion of battery technology for electric cars, health information technology, fuel cell buses, and retail developments (Dearlove 2001; Kelly 2010). For example:

- Tesla's entry into the electric car and battery industries has benefited from substantial federal and state subsidies (Wills 2014). The subsidized battery factory under construction in Nevada is expected to produce batteries that will support development of the electric car and solar power generation industries. If the subsidy strategy succeeds, this battery factory will induce subsequent entry by complementary firms that produce inputs into the battery production process and by firms that will contract with these suppliers to produce batteries in direct competition with Tesla.

- Short-term subsidies to spur development of nationwide Health Information Exchange (HIE) were included in the American Recovery and Reinvestment Act (ARRA) 2009. Blumenthal (2006) argued that Health Information Exchange (HIE) is a merit good that could provide the supporting infrastructure needed to increase efficiency in the U.S. healthcare industry, but development of the industry was blocked by coordination and learning externalities. ${ }^{1}$ Subsidies were provided to one pioneer HIE in each state, and federal policy explicitly stated that states should not block subsequent entrants into the HIE industry. It was anticipated that the pioneer HIE activities would spur adoption of complementary activities, including hospital and physician utilization of electronic medical records and healthcare payer utilization of population-health analytics. These complementary activities have merit-good characteristics, because they are expected to generate new types of efficiencies in the provision of healthcare services.

- The U.S. Supreme Court's controversial 2005 Kelo decision allows local governments to provide indirect subsidies to an individual firm, through the eminent domain process (Eagle 2009). The logic underlying this decision hinges on the expectation that market entry by the subsidized firm will generate benefits that induce subsequent entry by additional suppliers, customers and competitors. One component of the controversy generated by this decision focuses on the question of whether it is realistic to assume that the subsequent entry, and the hoped-for cost-reductions and price competition, will actually occur.

\footnotetext{
${ }^{1}$ Physician adoption of electronic medical records systems was low, partly because the infrastructure was not available to support exchange of electronic information among physician practices, and firms were not offering HIE services because most physicians did not have any electronic information to exchange.
} 
Despite the optimism embedded in these policies, the Pack and Saggi (2006) review of efforts to jump-start new industries (also known as sectoral targeting) concludes: "Few of the empirical analyses find that sectoral targeting has been particularly effective." Grossman (1989), Pack and Saggi (2006), and Rodriguez-Clare (2007) provide three potential explanations for this lack of evidence of successful implementation:

- political and rent-seeking pressures may push governments to target the short-term subsidies to industries that do not exhibit the characteristics defined by the marketfailure models,

- governments may not have sufficient information to accurately forecast the social value of developing technologies, or

- the initial short-term subsidy of the pioneer entrant may create a monopolist that blocks subsequent competitive entry by competitors and produces a suboptimal quantity of the merit good.

We focus on the third issue. We specify a two-period model in which the pioneer entrant's first period output reduces the second period production costs of both the pioneer and the potential subsequent entrant, due to knowledge gained through production experience, development of an efficient infrastructure for obtaining inputs, or education of potential customers.

The closely-related literatures on strategic trade policy and industrial policy provide the starting point for our model (Fudenberg and Tirole 1984, 1986; Neary and Leahy 2000; Pflüger and Südekum 2013). Fudenberg and Tirole (1984) and Neary and Leahy (2000) model output decisions of incumbent firms, focusing on entry and output decisions made by firms selling in both the domestic and "foreign" markets. Our model is similar, in spirit, to the Neary and Leahy (2000) framework in which the government cannot commit to future actions. However, we focus on a different question. Neary and Leahy (2000) model an industry with one "home" firm and one "foreign" firm, in which the home firm exports all of its output to compete against the "foreign" firm. In their model, the government seeks to maximize social welfare at "home", where the social welfare is equal to the present value of the "home" firm's profit. (See Pflüger and Südekum (2013) for additional analysis of policy designed to give domestic firms a competitive advantage in trade.)

We focus on a different situation; we model government policy designed to trigger development of a new merit good industry, that will produce and sell its output at "home". The policy goal is to induce a pioneer to enter (and create) the new industry, and to produce a level of first-period output that will induce subsequent entry by a second firm. Entry by the second firm is an important component of the policy goal: jump-starting the development of an efficient supply-chain infrastructure generates the cost reduction needed for long-term production of the merit-good, and jump-starting the development of a new multi-firm industry avoids the issues raised by monopoly provision of the merit good. We define a parameter that indicates the relationship between the outputs of the pioneer and subsequent entrant along the continuum between perfect complements and perfect substitutes. We derive two sets of results, that describe subsidy design to induce entry by an entrant that will produce complementary goods, and design that will induce competitive entry.

Our model focuses on a potential merit good industry, with two potential entrants: the pioneer will not enter in the first period without a subsidy, and the subsequent entrant will not 
enter without the cost reductions generated by the pioneer. These cost reductions stem from a diverse array of coordination and learning activities, and we streamline the remaining discussion by defining the term "learning" to encompass the full set of these activities. We assume that policy-makers have already concluded that jump-starting the new industry will generate a net benefit, and we examine conditions that determine whether the jump-start strategy will be successful. We examine the impact of a one-time intervention, designed to induce the entry needed to jumpstart development of an industrial complex of two firms producing complementary products or a new duopolistic industry comprised of two competitive firms. The volume of output produced by the pioneer entrant plays a key role in the design of both types of subsidies. Pioneer output quantity must exceed a threshold, to induce entry by complementary firms, while analysis of the output needed to induce competitive entry is more complex because the pioneer may engage in strategic behavior to solidify its initial monopoly position. We analyze whether such entry deterrence can be prevented by complementing the fixed subsidy with a one-period variable subsidy or tax.

\section{The Model}

We model a two-period game, in which the government acts as a Stackelberg leader, announcing fixed and variable subsidies to induce entry by the pioneer firm (firm $A$ ). If firm $A$ elects to enter the market, this pioneer entrant assumes the role of a Stackelberg leader, deciding how much to produce in the first production period with full awareness of the impact of period-1 output on the subsequent strategic interaction that will occur in period 2 between the pioneer (firm $A$ ) and the potential entrant (firm $B$ ). If the second firm enters in period 2, the two firms use Cournot strategies at that point in time. Thus, the government exerts direct influence on the production choice of the pioneer firm in period 1, but the government does not manage the competitive process directly in period 2. Instead, it influences the period-2 outputs of the firms indirectly (through its influence on the pioneer's initial output). The strategic interaction between the three parties is specified in the following timeline:

\section{Period 1:}

Date 1 The government chooses the levels of lump-sum $(S)$ and per unit $(v)$ subsidies, to induce firm $A$ to enter the market.

Date 2 Firm $A$ decides whether to enter the new market and chooses its level of period-1 production upon entry.

Period 2:

Date 3 Provided firm $A$ entered the market in period 1, firm $B$ decides whether to enter the market, and, subsequently, firm $A$ learns about firm $B$ 's entry decision.

Date 4 If firm $B$ enters, the two firms choose their production levels simultaneously and independently, using Cournot strategies. If firm $B$ does not enter, firm $A$ chooses the monopoly level of production.

The firms face inverse demand functions, $P_{i}^{t}=P_{i}\left(Q_{i}^{t}, Q_{j}^{t}\right)$, where $Q_{i}^{t}$ denotes the output of firm $i$ in period $t$, the superscript $t=1,2$ denotes the time period, and the subscript $i=A, B$ denotes the pioneer entrant (firm $A$ ) and the potential second entrant (firm $B$ ). Demand is 
assumed to be stationary across time to economize on notation. All functional forms in our model are twice-continuously differentiable in all of their arguments., ${ }^{2} 3$

The second firm does not contemplate entry in period 1 , because unsubsidized entry does not generate positive profits until learning occurs and firm $B$ is not eligible for the targeted subsidy; hence $Q_{B}^{1}=0$. It is also assumed that if firm $A$ finds it unprofitable to enter in period 1, then firm $B$ will stay out of the market in period 2. Finally, firm $A$ is assumed to remain in the market in period 2, if it was profitable for firm $A$ to enter the market in period 1 .

The pioneer firm faces relatively high production costs due to the absence of a welldeveloped network of suppliers, a shortage of potential employees with the specific skills needed by the new industry, and/or an innovator's steep learning curve. The pioneer firm's period-1 production activity provides the incentives and information needed to begin resolving these issues, and we coin all three types of problem-resolution as "learning". This "learning" may be completely internal to the pioneer, in which case the pioneer's period-1 output only generates a period-2 cost reduction for the pioneer. Alternatively, some of the "learning" may be shared by firm $B$, so that the new competitor firm splits the benefits from the pioneer's increased output in period 1. Thus, if both firms decide to enter the market, they may be linked via two mechanisms; the pioneer's period-1 output impacts the cost functions of both firms and the two firms sell goods that are either substitutes or complements.

The pioneer firm's cost function is $c_{A}^{1}\left(Q_{A}^{1}\right)$ in period 1 and the two firms' period-2 cost functions are represented by $c_{i}^{2}\left(Q_{i}^{2}, Q_{A}^{1}\right)$ because both firms can potentially learn from firm $A$ 's experience in period 1. The additional conditions that $\partial c_{A}^{1} / \partial Q_{A}^{1}, \partial^{2} c_{A}^{2} /$ $\partial Q_{A}^{2} \partial Q_{A}^{1}, \partial c_{B}^{2} / \partial Q_{A}^{1} \cdot \partial^{2} c_{B}^{2} / \partial Q_{B}^{2} / \partial Q_{A}^{1} \leq 0$ reflect our assumption that increases in firm $A^{\prime}$ s period-1 output generate learning that reduces both firms' total and marginal costs in period 2. Firm $A$ may potentially learn more than firm $B$, if most of the learning remains internal to firm $A$; hence the magnitudes of $\partial c_{A}^{2} / \partial Q_{A}^{1}$ and $\partial^{2} c_{A}^{2} / \partial Q_{A}^{2} \partial Q_{A}^{1}$ may be larger than the magnitudes of $\partial c_{B}^{2} / \partial Q_{A}^{1}$ and $\partial^{2} c_{B}^{2} / \partial Q_{B}^{2} \partial Q_{A}^{1}$, respectively. We also assume that the cost functions satisfy the usual curvature properties given by $\partial c_{A}^{1} / \partial\left(Q_{A}^{1}\right)^{2}, \partial^{2} c_{A}^{2} /$ $\partial\left(Q_{A}^{2}\right)^{2}, \partial^{2} c_{B}^{2} / \partial\left(Q_{B}^{2}\right)^{2}>0$. Finally, the pioneer and second entrant incur entry costs $E_{A}$ and $E_{B}$, respectively.

Our analysis of certain elements of the strategic interaction for Dates 2 through 4 (summarized in Lemmas 1 and 2) is similar to Fudenberg and Tirole $(1984,1986){ }^{4}$ The main innovation of the present work relative to the received literature on strategic entry deterrence lies in the modeling of the government's choices. Thus, the main value added of the paper from the technical point of view is contained in Sections 3.3 and 3.4. Since the analysis of the components of the game contained in these sections is interrelated with the other stages, we present an analysis of all parts of the strategic interaction. We focus on the implications of the strategic interaction for the feasibility of the jump-start strategy; hence we skip most of the steps in the exposition of the analysis common with Fudenberg and Tirole (1984, 1986), and we relegate the technical details to Appendix.

\footnotetext{
${ }^{2}$ Our results remain valid in a framework where the demand for firm A's product changes over time.

${ }^{3}$ It is also assumed that the profit functions of both firms are strictly concave.

${ }^{4}$ Our modeling of the spillover of firm A's period-1 output on choices in period 1 is slightly more general than that in Fudenberg and Tirole's model; however the mechanics of these models are applicable.
} 


\section{Equilibrium Behavior: Implications for the Jump-Start Strategy}

We solve the game backward, beginning with the proper subgames that start at Date 4 . The sequence of subgame solutions permits us to analyze the impact of firm $A$ 's period- 1 output on the period-2 Nash equilibrium outputs, on firm $B$ 's profit and entry decision, and on the feasibility of the jump-start strategy.

\subsection{Impact of the First Period Output on Production Decisions in Period 2 (Date 4)}

If firm $A$ enters the market in period 1 and firm $B$ enters the market in period 2, the period-2 profits of firms $A$ and $B$ are given by:

$$
\pi_{i}^{2}\left(Q_{i}^{1}, Q_{i}^{2}, Q_{j}^{2}\right)=R_{i}\left(Q_{i}^{2}, Q_{j}^{2}\right)-c_{i}^{2}\left(Q_{i}^{2}, Q_{j}^{2}\right)-E_{i}
$$

where $R_{i}\left(Q_{i}^{2}, Q_{j}^{2}\right)$ denotes player $i$ 's revenue, $j \neq i$, and $Q_{B}^{1}=0$. When both firms are in the market in period 2, they compete in a Cournot fashion. The Nash equilibrium $\left(\hat{Q}_{A}^{2}\left(Q_{A}^{1}\right), \hat{Q}_{B}^{2}\right.$ $\left.\left(Q_{A}^{1}\right)\right)$ of the Date-4 subgame is given by the solution to:

$$
\frac{\partial R_{A}\left(\hat{Q}_{A}^{2}, \hat{Q}_{B}^{2}\right)}{\partial Q_{A}^{2}}=\frac{\partial c_{A}\left(\hat{Q}_{A}^{2}, \partial Q_{A}^{1}\right)}{\partial Q_{A}^{2}} \text { and } \frac{\partial R_{B}\left(\hat{Q}_{B}^{2}, \hat{Q}_{A}^{2}\right)}{\partial Q_{B}^{2}}=\frac{\partial c_{B}\left(\hat{Q}_{B}^{2}, \partial Q_{A}^{1}\right)}{\partial Q_{B}^{2}}
$$

We assume that an interior solution exists, and the Nash Equilibrium is asymptotically stable. The asymptotic stability requires $\frac{\partial M R_{A} / \partial Q_{B}^{2}}{S O D_{A}} \cdot \frac{\partial M R_{B} / \partial Q_{A}^{2}}{S O D_{B}}<1 \mathrm{~S}$ for all $\left(Q_{A}^{2}, Q_{B}^{2}\right)$ in some open neighborhood of the Nash equilibrium of the date-4 subgame (Fudenberg and Tirole 1991), where $S O D_{i}$ represents the second-order derivative of firm $i$ 's profit with respect to own output, and the term $M R_{i}$ represents marginal revenue for firm $i$.

If firm $B$ stays out in period 2, then firm $A$ will choose the monopoly output level $\bar{Q}_{A}^{2}\left(Q_{A}^{1}\right)$ given by

$$
\frac{\partial R_{A}\left(\bar{Q}_{A}^{2}, 0\right)}{\partial Q_{A}^{2}}=\frac{\partial c_{A}^{2}\left(\bar{Q}_{A}^{2}, Q_{A}^{1}\right)}{\partial Q_{A}^{2}}
$$

The jump-start strategy focuses on the impact of $Q_{A}^{1}$ on the period 2 outputs of firms $A$ and $B$. As detailed in the following lemma, when the goods are substitutes, outputs chosen the by firms $A$ and $B$ depend on the ratio of external to internal learning. Internal learning, given by $L_{A}=\partial^{2} c_{B}^{2}\left(\hat{Q}_{B}^{2}, Q_{A}^{1}\right) / \partial Q_{A}^{2} \partial Q_{A}^{1}$, measures the impact of the pioneer's period-1 activities on the pioneer's own marginal cost curve in period 2. External learning, given by $L_{A}=\partial^{2} c_{B}^{2}$ $\left(\hat{Q}_{B}^{2}, Q_{A}^{1}\right) / \partial Q_{B}^{2} \partial Q_{A}^{1}$, measures the impact of the pioneer's period-1 activities on firm $B$ 's period-2 marginal cost curve. We have:

Lemma 1: Impact of the first period output on production decisions in period 2

(a) If the goods are complements, then an increase in firm A's output in period 1 will result in an increase in the outputs of both firms in period 2. 
(b) If the goods are substitutes, then an increase in firm A's period-1 output will result in:

(b-i) increases in the outputs of both firms in period 2 if and only if

$$
\frac{\partial M R_{B} / \partial Q_{A}^{2}}{S O D_{A}} \leq \frac{L_{B}}{L_{A}} \leq \frac{S O D_{B}}{\partial M R_{A} / \partial Q_{B}^{2}}
$$

(b-ii) a decrease in firm A's period-2 output and an increase in firm $B$ 's period-2 output if and only if the ratio of external learning to internal learning exceeds a threshold:

$$
\frac{S O D_{B}}{\partial M R_{A} / \partial Q_{B}^{2}} \leq \frac{L_{B}}{L_{A}}
$$

(b-iii) an increase in firm A's period-2 output and a decrease in firm $B$ 's period-2 output if and only if the ratio of external learning to internal learning is low:

$$
\frac{L_{B}}{L_{A}} \leq \frac{\partial M R_{B} / \partial Q_{A}^{2}}{S O D_{A}}
$$

Furthermore, it is never the case that an increase in firm A's period-1 output results in decreases in period- 2 outputs of both firms. ${ }^{5}$

\section{Proof: See Appendix}

Lemma 1 highlights the critical role of the relationship between learning that is shared by firm $B$ and learning that remains internal to firm $A$ : the ratio of these two variables defines the conditions under which $Q_{A}^{1}$ exerts positive (or negative) impacts on period-2 Nash equilibrium outputs $\hat{Q}_{A}^{2}$ and $\hat{Q}_{B}^{2}$, when both firms are in the market in period 2. The magnitude of firm $B$ 's period-2 output is important because policy-makers employ the jump-start strategy to develop industries that produce merit goods. This implies that policy-makers value industry growth, along with low production costs and competitive pricing.

The result summarized in Lemma 1 can be interpreted graphically, by considering the impacts of period-1 output on the best-response curves. When the goods produced by the two firms are strategic complements (Bulow et al. 1985), an increase in $Q_{A}^{1}$ results in a downward shift of firm A's best response curve and an upward shift of firm $B$ 's best response curve. As a result, the new Nash equilibrium involves higher production by both firms. This result is a basic property of supermodular games (Topkis 1979, 1998; Bulow et al. 1985; Milgrom and Roberts 1990; Vives 1990).

In the case of strategic substitutes, the effects of $Q_{A}^{1}$ on the period-2 production levels are ambiguous. The downward-sloping best-response curves of both firms shift upward as a result of an increase in $Q_{A}^{1}$. The relationship between the original and new Nash equilibria depends on the relative magnitude of the two upward shifts and the curvature of the best-response curves. The shifts are driven by the ratio of external to internal learning: the more each firm "learns" the greater the shift of its best response curve. Each curve's upward shift will tend to

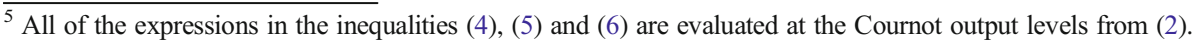


increase that firm's Nash equilibrium production level and decrease its counterpart's production. Because both firms "learn" and the two firms" "learning" work in opposite directions, the total effect is ambiguous.

In summary, the period- 2 outputs of both firms are increasing functions of firm $A$ 's period-1 production when the pioneer and the subsequent entrant produce complementary good. When the two firms produce substitutes, however, the impact of firm A's period-1 production on second-period output hinges on the relationship between internal and external learning. Firm $A$ 's period-2 production increases when (i) firm $B$ 's external learning is low $\left(L_{B} / L_{A}\right)$ is relatively small), (ii) firm $B$ 's best response is relatively unresponsive to changes in firm $A$ 's output, and (iii) the marginal effect of firm $A$ 's period-2 output on the marginal revenue of firm $B$ is large compared to the marginal effect of firm $B$ 's period-2 output on the marginal revenue of firm $A$. Analogous results hold for firm $B$. It also follows from Lemma 1 that the increased period-1 output will only trigger period-2 expansion of both $Q_{A}^{2}$ and $Q_{B}^{2}$ when the internal-learning ratio is bounded by the ratios of the impacts of $Q_{A}^{2}$ on the two firms' profits and the impacts of $Q_{B}^{2}$ on the two firms' profits., ${ }^{6} 7$

\subsection{Impact of Period-1 Output on Firm B's Entry Decision (Date 3)}

Firm $B$ 's entry decision is a critical target of the jump-start strategy. Firm $B$ 's profit is negative when $Q_{A}^{1}=0$ by assumption, and firm $B$ will only enter in period 2 if it anticipates earning a positive profit. Given $Q_{A}^{1}$, firm $B$ will enter the market at Date 3 if and only if:

$$
\pi_{B}=R_{B}\left(\hat{Q}_{A}^{2}\left(Q_{A}^{1}\right), \hat{Q}_{B}^{2}\left(Q_{A}^{1}\right)\right)-c_{B}\left(\hat{Q}_{B}^{2}\left(Q_{A}^{1}\right), Q_{A}^{1}\right)-E_{B} \geq 0
$$

Differentiating (7) with respect to $Q_{A}^{1}$ and using (2) we obtain:

$$
\frac{d \pi_{B}}{d Q_{A}^{1}}=-\frac{\partial c_{B}\left(\hat{Q}_{B}^{2}\left(Q_{A}^{1}\right), Q_{A}^{1}\right)}{\partial Q_{A}^{1}}+\frac{\partial R_{B}\left(\hat{Q}_{A}^{2}\left(Q_{A}^{1}\right), \hat{Q}_{B}^{2}\left(Q_{A}^{1}\right)\right)}{\partial Q_{A}^{2}} \frac{d \hat{Q}_{A}^{2}\left(Q_{A}^{1}\right)}{d Q_{A}^{1}}
$$

where $\frac{d \hat{Q}_{A}^{2}\left(Q_{A}^{1}\right)}{d Q_{A}^{\perp}}$ is characterized in Lemma 1. This expression reveals that an increase in $Q_{A}^{1}$ exerts direct and indirect impacts on firm $B$ 's period-2 profit: the direct effect of "learning" on $\pi_{B}$ given by the first term in (8) and the strategic effect given by the second term in (8), respectively (Fudenberg and Tirole 1984). The direct impact of $Q_{A}^{1}$ on firm $B$ 's period-2 profit is positive. If the goods produced by the two firms are complements, then the strategic effect is also positive. If the goods are substitutes, the direction of the strategic effect depends on the sign of $\frac{d \hat{Q}_{A}^{2}\left(Q_{A}^{1}\right)}{d Q_{A}^{1}}$. When $\frac{d \hat{Q}_{A}^{2}\left(Q_{A}^{1}\right)}{d Q_{A}^{1}}<0$, the impact of $Q_{A}^{1}$ on $\pi_{B}$ is unambiguously positive.

\footnotetext{
${ }^{6}$ For readers familiar with the Neary-Leahy conceptual framework, our scenario roughly corresponds to the Neary-Leahy case of "research and development with spillovers between firms", with the exception that we focus on a different policy goal.

${ }^{7}$ Note that part (b) of Lemma 1 is a local result since the relative rankings of the terms in (4), (5) and (6) are functions of firm A's first period output.
} 
However, when $\frac{d \hat{Q}_{A}^{2}\left(Q_{A}^{1}\right)}{d Q_{A}^{1}}<0$, the impact of $Q_{A}^{1}$ on $\pi_{B}$ depends on the relative magnitudes of the direct and strategic effects. We detail this result in Lemma 2:

Lemma 2: Impact of $Q_{A}^{1}$ on firm B's profit

(a) If the goods produced by firms $A$ and $B$ are complements, then firm $B$ 's profit is increasing in $Q_{A}^{1}$. Hence, firm $B$ will enter if and only if firm $A$ 's output in period 1 is sufficiently large. ${ }^{8}$

(b) If the goods produced by firms $A$ and $B$ are substitutes, then $\frac{d \pi_{B}}{d Q_{A}^{1}}>0$ if and only if

$$
\frac{L_{A} S O D_{B}-L_{B}\left(\partial M R_{A} / \partial Q_{B}^{2}\right)}{S O D_{A} S O D_{B}-\left(\partial M R_{A} / \partial Q_{B}^{2}\right)\left(\partial M R_{B} / \partial Q_{A}^{2}\right)} \leq \frac{\partial c_{B} / \partial Q_{A}^{1}}{\partial R_{B} / \partial Q_{A}^{2}}
$$

which is satisfied when $\frac{d \hat{Q}_{A}^{2}}{d Q_{A}^{1}} \leq 0$.

The magnitude of the right-hand-side of inequality (9) depends on the two pathways through which firm $A$ 's activities impact firm $B$ 's profit: Firm $A$ 's period-1 output generates learning that reduces firm $B$ 's second-period cost, while firm $A$ 's period-2 output affects the demand for firm $B$ 's product. When the two goods are substitutes, the condition $\frac{d \hat{Q}_{A}^{2}}{d Q_{A}^{1}} \leq 0$ from Lemma 1 is sufficient, but not necessary, to ensure that inequality (9) is satisfied. If $\frac{d \hat{Q}_{A}^{2}}{d Q_{A}^{1}} \leq 0$, policy makers can assume that subsidies designed to increase $Q_{A}^{1}$ will not have a deleterious impact on firm $B$ 's period-2 market share. If condition (9) is satisfied with $\frac{d \hat{Q}_{A}^{2}}{d Q_{A}^{1}}>0$, however, policy makers would face a dilemma: policies designed to induce the increase in $Q_{A}^{1}$ needed to induce entry by firm $B$ will also dampen firm $B$ 's period- 2 market share. This could be problematic, if policy makers are concerned that the subsidized firm could wield long-term market power.

\subsection{Firm A's Period-1 Decisions (Date 2)}

If firm $A$ decides to enter the market in period 1, it sets $Q_{A}^{1}$ at Date 2 . When firm $A$ considers its period-1 output decision, it realizes that some values of $Q_{A}^{1}$ will deter firm $B$ 's entry, while others will facilitate entry. We examine this decision by defining $I^{D}$ to be the set of values of $Q_{A}^{1}$ for which firm $B$ finds it profitable to enter in period 2 (and the two firms function as duopolists). In contrast, firm $B$ 's entry is deterred and firm $A$ continues to operate as a monopolist if firm A's period-1 output choice belongs to the complement of set $I^{D}$, which is denoted by $I^{M}$. When the goods produced by the two firms are strategic complements, the set $I^{D}$ consists of all values of $Q_{A}^{1}$ that exceed some threshold level. The structure of the two sets can be more complex when the goods produced by firms $A$ and $B$ are substitutes, as detailed below.

\footnotetext{
${ }^{8}$ In this part and what follows, we implicitly assume that firm $B$ 's entry cost is not so high as to prevent its entry for any level of firm A's period-1 output.
} 
Because firm $A$ realizes that $Q_{A}^{1}$ may facilitate or deter $B$ 's subsequent entry, it compares the level of $C$ that would maximize its profits if it remains a monopolist with the output level that would maximize its profits if firm $B$ entered. Firm $A$ 's two-period stream of profits (assuming a zero discount rate) for $Q_{A}^{1} \in I^{D}$ is

$$
\begin{gathered}
\pi^{D}\left(Q_{A}^{1} ; v, S\right) \equiv\left[R_{A}\left(Q_{A}^{1}, 0\right)+v Q_{A}^{1}+S-c_{A}^{1}\left(Q_{A}^{1}\right)-E_{A}\right] \\
+\left[R_{A}\left(\hat{Q}_{A}^{2}\left(Q_{A}^{1}\right), \hat{Q}_{B}^{2}\left(Q_{A}^{1}\right)\right)-c_{A}^{2}\left(\hat{Q}_{A}^{2}\left(Q_{A}^{1}\right), Q_{A}^{1}\right)\right]
\end{gathered}
$$

Alternatively, if firm $B$ stays out $\left(Q_{A}^{1} \in I^{M}\right)$, firm $A$ 's two-period stream of profits is

$$
\begin{aligned}
& \pi^{M}\left(Q_{A}^{1} ; v, S\right) \equiv\left[R_{A}\left(Q_{A}^{1}, 0\right)+v Q_{A}^{1}+S-c_{A}^{1}\left(Q_{A}^{1}\right)-E_{A}\right] \\
& +\left[R_{A}\left(\bar{Q}_{A}^{2}\left(Q_{A}^{1}\right), 0\right)-c_{A}^{2}\left(\hat{Q}_{A}^{2}\left(Q_{A}^{1}\right), Q_{A}^{1}\right)\right]
\end{aligned}
$$

where $\bar{Q}_{A}^{1}$ is the optimal output if firm $A$ is a monopolist in period 2.

Let $\hat{Q}_{A}^{1}(v) \equiv \operatorname{argmax}_{Q_{A}^{1} \geq 0} \pi^{D}\left(Q_{A}^{1} ; v, S\right)$ denote the level of output that firm $A$ would choose if it were certain that firm $B$ would enter the market in period 2, irrespective of its period-1 output. Also, let $\bar{Q}_{A}^{1}(v) \equiv \operatorname{argmax}_{Q_{A}^{1} \geq 0} \pi^{M}\left(Q_{A}^{1} ; v, S\right)$ denote the level of output that firm $A$ would choose if it were certain that firm $B$ would stay out of the market in period 2, irrespective of its period-1 output. On some occasions, we subsume the dependence of $\hat{Q}_{A}^{1}(v)$ and $\bar{Q}_{A}^{1}(v)$ on the per-unit subsidy to preserve compactness of the formulas. In what follows, we denote the duopoly and monopoly outputs as $\hat{Q}_{A}^{1}$ and $\bar{Q}_{A}^{1}$, respectively. We examine these "unconditional" profit functions and the corresponding optimal choices to facilitate the subsequent analysis of the equilibrium behavior. Firm $A$ 's first period equilibrium output may differ from both $\hat{Q}_{A}^{1}$ and $\bar{Q}_{A}^{1}$ because firm $B$ 's entry decision creates a discontinuity in firm $A$ 's profit function. Firm $A$ 's optimal output level in period 1 is given by

$$
\left\{\begin{array}{l}
\operatorname{argmax}_{Q_{A}^{1} \in I^{M}} \pi^{M}\left(Q_{A}^{1} ; v, S\right), \text { if } \max _{Q_{A}^{1} \in I^{M}} \pi^{M}\left(Q_{A}^{1} ; v, S\right) \geq \max _{Q_{A}^{1} \in I^{D}} \pi^{D}\left(Q_{A}^{1} ; v, S\right) \\
\operatorname{argmax}_{Q_{A}^{1} \in I^{D}} \pi^{D}\left(Q_{A}^{1} ; v, S\right), \text { if } \max _{Q_{A}^{1} \in I^{M}} \pi^{M}\left(Q_{A}^{1} ; v, S\right)<\max _{Q_{A}^{1} \in I^{D}} \pi^{D}\left(Q_{A}^{1} ; v, S\right)
\end{array}\right.
$$

where $v$ represents a variable subsidy and $S$ represents a lump sum subsidy. We focus on the case in which the sets $I^{D}$ and $I^{M}$ are both bounded intervals and the unique boundary of the two sets is given by the unique ${ }^{9}$ positive solution $\tilde{Q}_{A}^{1}$ to:

$$
R_{B}\left(\hat{Q}_{A}^{2}\left(Q_{A}^{1}\right), \hat{Q}_{B}^{2}\left(Q_{A}^{1}\right)\right)-c_{B}\left(\hat{Q}_{B}^{2}\left(Q_{A}^{1}\right), Q_{A}^{1}\right)-E_{B}=0
$$

Under (13), firm $B$ is indifferent between staying out and entering the market in period 2. The boundary $\tilde{Q}_{A}^{1}$ is independent of both the lump-sum and per-unit subsidies, because firm $B$ will not receive either subsidy. The relationship between $\hat{Q}_{A}^{1}$ and $\bar{Q}_{A}^{1}$ is characterized in

\footnotetext{
${ }_{9}$ The solution may not be unique. We assume uniqueness to streamline the discussion.
} 


\section{Lemma 3: Relationship between the monopoly and duopoly output levels}

(a) If the goods are complements then $\bar{Q}_{A}^{1} \leq \hat{Q}_{A}^{1}$.

(b) If the goods are substitutes then

(b-i) If $\frac{\partial \hat{Q}_{B}^{2}\left(\bar{Q}_{A}^{1}\right)}{\partial \hat{Q}^{2}\left(\bar{Q}_{A}^{1}\right)} \geq 0$, then $\hat{Q}_{A}^{1} \leq \bar{Q}_{A}^{1}$.

(b-ii) If $\frac{\partial \hat{Q}_{B}^{2}\left(\bar{Q}_{A}\right)}{\partial Q_{A}^{1}}<0$, the relationship between $\hat{Q}_{A}^{1}$ and $\bar{Q}_{A}^{1}$ is ambiguous.

\section{Proof: See Appendix}

We use Lemma 3 to explore whether a fixed subsidy that induces pioneer entry by firm A can ensure that firm $A$ will choose $Q_{A}^{1}$ that will induce subsequent entry by firm $B$. Figure $1 \mathrm{a}-\mathrm{c}$ illustrate the logic for the case in which the two firms produce complementary goods, and Fig. 2a-c illustrate the logic for the case in which the outputs of the two firms are substitute goods. The relative positions of the duopoly and monopoly profit functions, $\pi^{D}\left(Q_{A}^{1} ; v, S\right)$ and $\pi^{M}\left(Q_{A}^{1} ; v, S\right)$, are determined by the market relationship between the two firms' outputs. The profit function $\pi^{D}$ lies above $\pi^{M}$ when the two firms sell complementary goods, and the relationship is reversed when the firms sell substitutes. The bold sections of the profit curves represent firm $A$ 's profit, after accounting for firm $B$ 's entry decision.

\subsubsection{Complements}

When the goods are strategic complements, firm $B$ 's profit is a positive function of $Q_{A}^{1}$ (from Lemma 2). Therefore, firm $B$ will enter if and only if firm $A$ 's period-1 output is sufficiently large. Thus, the sets $I^{D}$ and $I^{M}$ are defined as $I^{D}=\left[\tilde{Q}_{A}^{1}, Z\right]$ and $I^{M}=\left[0, \tilde{Q}_{A}^{1}\right]$, where $Z$ is the upper bound of the feasible first-period outputs. Three scenarios, which are defined by the relationships among $\hat{Q}_{A}^{1}, \bar{Q}_{A}^{1}$ and $\tilde{Q}_{A}^{1}$, are illustrated in Fig. 1a-c. If $\hat{Q}_{A}^{1} \geq \tilde{Q}_{A}^{1}$, firm A's optimal output will induce subsequent entry by firm $B$, and the two firms will be Cournot duopolists in period 2. In this case, the value of $Q_{A}^{1}$ that maximizes firm $A$ 's profit "unintentionally" stimulates firm $B$ entry, as illustrated in Fig. 1a. If $\hat{Q}_{A}^{1}<\tilde{Q}_{A}^{1}$, however, firm $A$ will compare the maximum monopoly profits, given by $\pi^{M}\left(\bar{Q}_{A}^{1} ; v, S\right)$, with its duopoly profit $\pi^{D}\left(\bar{Q}_{A}^{1} ; v, S\right)$. Two additional outcomes are possible when $\hat{Q}_{A}^{1}<\tilde{Q}_{A}^{1}$, depending on the relationship between $\pi^{M}\left(\bar{Q}_{A}^{1} ; v, S\right)$ and $\pi^{D}\left(\bar{Q}_{A}^{1} ; v, S\right)$, as illustrated in Fig. 1b and c. If $\pi^{M}\left(\bar{Q}_{A}^{1} ; v, S\right)<\pi^{D}\left(\tilde{Q}_{A}^{1} ; v, S\right)$, firm $A$ will “intentionally" induce entry of firm $B$ by producing $\tilde{Q}_{A}^{1}$ (see Fig. 1b). However, if $\pi^{M}\left(\bar{Q}_{A}^{1} ; v, S\right)<\pi^{D}\left(\tilde{Q}_{A}^{1} ; v, S\right)$, as illustrated in Fig. 1c, firm $A$ will produce $\bar{Q}_{A}^{1}$ in period 1 and "unintentionally" deter entry by firm $B$. This will occur when the degree of complementarity between the two goods is relatively low.

Note that that a fixed subsidy does not affect which of the above three cases materializes. Instead, the occurrence of case $\mathrm{a}, \mathrm{b}$ or $\mathrm{c}$ is determined by the relationship between the level of

Fig. 1 a: Firm $A$ 's profit as a function of its period-1 production: complements and firm $A$ "unintentionally" stimulates firm $B$ 's entry. b: Firm $A$ 's profit as a function of its period-1 production: complements and firm $A$ “intentionally" stimulates firm $B$ 's entry. c: Firm $A$ 's profit as a function of its period-1 production: complements and firm $A$ "unintentionally" deters firm $B$ 's entry 

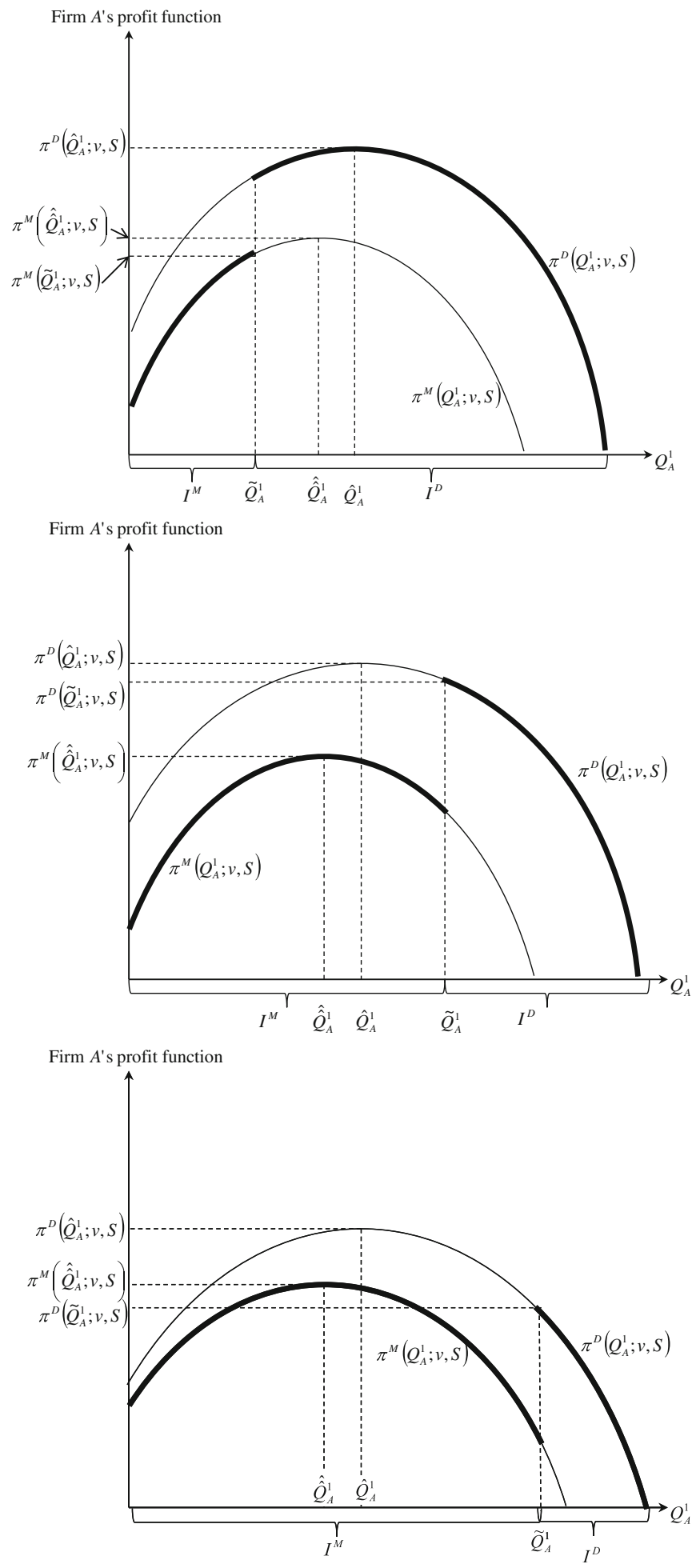
Fig. 2 a: Firm $A$ 's profit as a function of its period-1 production: substitutes and firm $A$ "unintentionally" deters firm $B$ 's entry. b: Firm $A$ 's profit as a function of its period-1 production: substitutes and firm $A$ "intentionally" deters firm $B$ 's entry. c: Firm $A$ 's profit as a function of its period-1 production: substitutes and firm $A$ "unintentionally" stimulates firm $B$ 's entry

period-one output that maximizes the pioneer's profit and the level of period-one output at which the potential entrant's profit is equal to zero. Hence, a fixed subsidy by itself will not necessarily induce subsequent entry - even when the firms produce complementary goods. When firm $A$ maximizes profit by setting $Q_{A}^{1}$ at a level that deters firm $B$ 's subsequent entry, it will be necessary to augment the fixed subsidy with a variable subsidy, as discussed below in Section 3.4 .

\subsubsection{Substitutes}

For the case of substitutes, $\pi^{D}$ lies below $\pi^{M}$ because firm $B$ 's output competes with the pioneer's output. We consider two configurations of the sets $I^{D}$ and $I^{M}$ : in the first scenario, $I^{M}=\left[0, \tilde{Q}_{A}^{1}\right]$ and $I^{D}=\left[\tilde{Q}_{A}^{1}, Z\right]$ so that firm $B$ enters if and only if firm $A$ 's period-1 output is sufficiently large; and in the second scenario, $I^{D}=\left[0, \tilde{Q}_{A}^{1}\right]$ and $\mathrm{I}^{M}=\left[\tilde{Q}_{A}^{1}, Z\right]$ and $\mathrm{I}^{M}=\left[\tilde{Q}_{A}^{1}, Z\right]$. The analysis of the first scenario echoes the discussion presented above for complementary goods; hence the details are omitted.

We focus, therefore, on the case in which firm $B$ enters if and only if firm $A$ 's period-1 output is sufficiently small; $I^{D}=\left[0, \tilde{Q}_{A}^{1}\right]$ and $\mathrm{I}^{M}=\left[\tilde{Q}_{A}^{1}, Z\right]$. As illustrated in Fig. 2a, when $\tilde{Q}_{A}^{1}, \leq \bar{Q}_{A}^{1}$, firm $A$ will set its period-1 output equal to the monopoly level $\bar{Q}_{A}^{1}$. In this case, firm $A$ 's actions are identical to the "business as usual" behavior where firm $A$ does not face potential competition in period 2 and it has a monopoly position in both periods. Firm $B$ is "unintentionally" deterred by firm $A$ 's actions.

Figure 2b depicts the case in which $\tilde{Q}_{A}^{1}>\bar{Q}_{A}^{1}$ and $\pi^{M}\left(\tilde{Q}_{A}^{1} ; v, S\right)>\pi^{D}\left(\tilde{Q}_{A}^{1} ; v, S\right)$. In this case, firm $A$ cannot enjoy a monopoly position by choosing $\bar{Q}_{A}^{1}$. Instead, firm $A$ chooses between either producing $\hat{Q}_{A}^{1}$ and earning the duopoly profit, or deterring entry by producing any quantity greater than $\tilde{Q}_{A}^{1}$ and earning the monopoly profit. Because the monopoly profit in Fig. $2 \mathrm{~b}$ exceeds the duopoly profit, firm $A$ will "intentionally" deter firm $B$ 's entry. Thus, pioneer entry spurred by a fixed subsidy will not generate subsequent entry by firm $B$ in the cases depicted in Fig. $2 \mathrm{a}$ and $\mathrm{b}$.

However, firm $A$ will "unintentionally" stimulate entry of firm $B$ when $\tilde{Q}_{A}^{1}>\bar{Q}_{A}^{1}$ and $\pi^{M}$ $\left(\tilde{Q}_{A}^{1} ; v, S\right)>\pi^{D}\left(\tilde{Q}_{A}^{1} ; v, S\right)$ (see Fig. 2c). In this case, a one-time lump-sum subsidy will be sufficient to jump-start a multi-firm industry.

In summary, firm $B$ 's period-2 profit is a function of firm $A$ 's period- 1 output. There is no guarantee that firm $A$ will elect to produce a level of period-1 output that will induce secondperiod entry by firm $B$. Firm $A$ may deter subsequent entry of both competitors and firm providing complementary goods, and this deterrence may result from non-strategic Cournotmaximization of profit. 

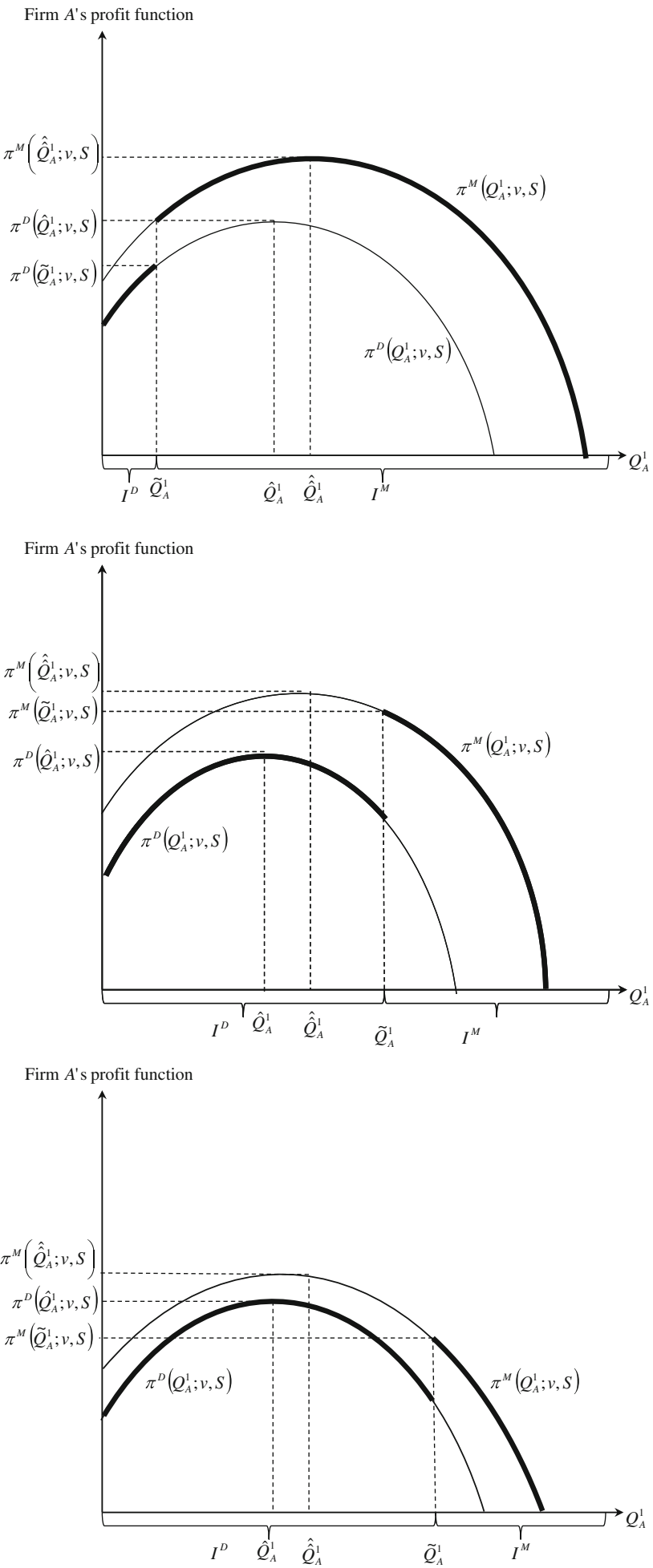


\subsection{Subsidy Design: A Fixed Subsidy, Augmented with a Per-Unit Subsidy or Tax (Date 1)}

These results raise the question, can the government successfully jumpstart a multi-firm industry by augmenting the lump sum subsidy with a per-unit subsidy? To analyze this question, we now suppose that the government deploys two policy instruments, a per-unit subsidy and a lump sum subsidy, and it intentionally restricts the use of these subsidies to the first period. While the lump sum subsidy will only impact firm $A$ 's entry decision, the variable subsidy $v$ has four effects ${ }^{10}$ on the social welfare in periods 1 and 2 , through its effect on $Q_{A}^{1}$ :

- $\quad v$ affects producer and consumer surplus in period 1 ,

- $\quad v$ affects "learning", which has a direct effect on social welfare in period 2, through its impact on period-2 production costs,

- $\quad v$ affects "learning" which has an indirect effect on social welfare in period 2, through its effect on the potential strategic interaction between firms $A$ and $B$ in period 2, and

- $\quad v$ affects social welfare in period 2 , through its impact on the duopoly vs. monopoly market structure in period 2.

From the perspective of the first and second effects, the government has an incentive to choose a per-unit subsidy over a per-unit tax. The direction of the third effect depends on whether "learning" fosters or hinders competition ${ }^{11}$ in period 2. We focus only on the fourth effect due to space considerations and because addition of an extra firm to the market is likely to have a greater impact on welfare than changes associated with variation in the output of a single firm.

To analyze the government's ability to jump-start a multi-firm industry we use Fig. 3 and refer back to Figs. 1c, 2a and b. An increase in the variable subsidy $v$ will cause both profit curves $\pi^{M}\left(\tilde{Q}_{A}^{1} ; v, S\right)$ and $\pi^{D}\left(\tilde{Q}_{A}^{1} ; v, S\right)$ to shift upward leaving unchanged the threshold level $\tilde{Q}_{A}^{1}$. The shift in each profit function is equal to $v \cdot Q_{A}^{1}>0$. Therefore, the upward shifts of the profit functions that result from increasing $v$ increase with $Q_{A}^{1}$, and the magnitudes of the vertical shifts in the two profit functions are equal for any given level of $Q_{A}^{1}$. It also follows from the functional forms for $\pi^{M}\left(\tilde{Q}_{A}^{1} ; v, S\right)$ and $\pi^{D}\left(\tilde{Q}_{A}^{1} ; v, S\right)$ that both $\hat{Q}_{A}^{1}$ and $\bar{Q}_{A}^{1}$ increase in response to an increase in $v$. These observations have important implications for firm $A$ 's entry deterring behavior and the government's ability to induce entry of firm $B$.

First, consider the case of strategic complements (see Fig. 1a-c). If firm A's profit function has the form depicted in Fig. 1a or b when $v=0$, then firm $B$ will enter the market in period 2 and, hence, there will be no need for the government to supplement a lump sum subsidy with a per unit subsidy. An appropriately chosen fixed subsidy $S$ will be sufficient to induce entry by firm $A$, and that entry will stimulate subsequent entry by firm $B$. Consider now the case depicted in Figs. 1c and 3. In this case, an increase in the per-unit subsidy $v$ will result in an upward shift of point $\pi^{D}\left(\tilde{Q}_{A}^{1} ; v, S\right)$ that exceeds the upward shift of monopoly profit for output levels in $I^{M}=\left[0, \tilde{Q}_{A}^{1}\right]$. Hence, the government can induce the duopoly outcome by

\footnotetext{
${ }^{10}$ In our discussion, we abstract away from the shadow cost of raising public funds to jump-start a multi-firm industry.

${ }^{11}$ If "learning" by the two firms is disproportionate then a per-unit subsidy in period 1 may inhibit competition.
} 


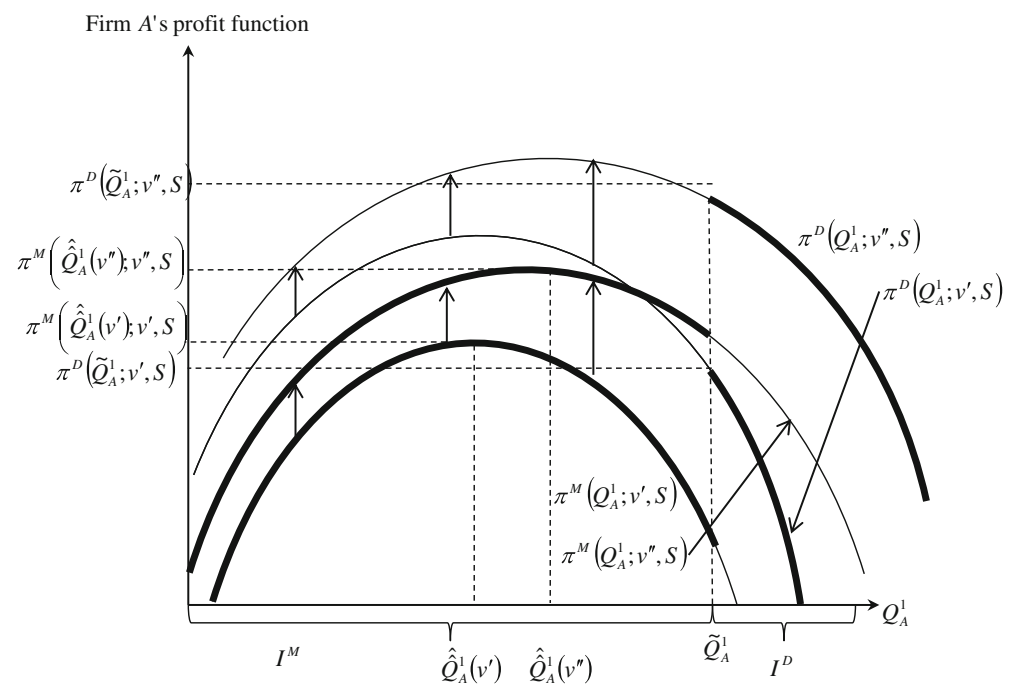

Fig. 3 The impact of an increase in the per-unit subsidy from $v^{\prime}$ to $v^{\prime \prime}$ : complements

providing a sufficiently large per-unit subsidy to the pioneer entrant. The logic is analogous when the goods produced by the two firms are substitutes and $I^{M}=\left[0, \tilde{Q}_{A}^{1}\right]$ and $I^{D}=\left[0, \tilde{Q}_{A}^{1}\right]$; hence the government can jump-start a multi-firm industry by instituting a sufficiently large period-1 per-unit subsidy.

We now turn to the case of strategic substitutes with $I^{D}=\left[0, \tilde{Q}_{A}^{1}\right]$ and $I^{M}=\left[\tilde{Q}_{A}^{1}, Z\right]$ (see Fig. 2a-c). Under this scenario, firm $B$ 's profit is a decreasing function of $Q_{A}^{1}$, because a relatively large share of the learning is internal to the pioneer firm (see part (b) of Lemma 2), and the degree of substitution between the two goods is high relative to the proportion of learning that is shared. First, consider the case depicted in Fig. 2a and suppose that the government introduces a period-1 per-unit tax. This will result in leftward shifts of both $\hat{Q}_{A}^{1}$ and $\bar{Q}_{A}^{1}$. Furthermore, the curves $\pi^{D}(\cdot ; v, S)$ and $\pi^{M}(\cdot ; v, S)$ will shift downward and proportionately to the output level at which they are evaluated. Since period-1 output levels that induce duopoly are lower than the output levels that result in a monopoly, the duopoly outcome will become more attractive as the per-unit tax increases. For a sufficiently large per-unit tax the duopoly outcome will entail a larger profit. Note, however, that per-unit taxes that can make the duopoly outcome more attractive may be so large that the pioneer firm will prefer to stay out of the market altogether. To prevent such behavior, the government will need to offset the per-unit tax with a sufficiently large period-1 lump sum subsidy and a requirement that to qualify for the lump-sum subsidy the pioneer firm will have to produce a period-1 output above some strictly positive level.

We summarize all of our findings in the following:

Proposition: Feasibility of jump-starting a multi-firm industry.

(a) If the goods produced by the two firms are complements, the government can jump-start a multi-firm industry by implementing a combination of fixed and variable one-time subsidies. 
(b) If the goods produced by the two firms are substitutes, the government may need to impose an additional requirement.

(b-i) If, $I^{M}=\left[0, \tilde{Q}_{A}^{1}\right]$ and $I^{D}=\left[\tilde{Q}_{A}^{1}, Z\right]$ then the government can jump-start a multifirm industry by implementing a sufficiently high period-1 per-unit subsidy to the pioneer entrant.

(b-ii) If, $I^{D}=\left[0, \tilde{Q}_{A}^{1}\right]$ and $I^{M}=\left[\tilde{Q}_{A}^{1}, Z\right]$ then the government can jump-start a multifirm industry by implementing a sufficiently high period-1 per-unit tax to the pioneer entrant balanced by a sufficiently large lump-sum subsidy and a requirement that the pioneer firm needs to produce period-1 output above some strictly positive level.

When the goods produced by the two firms are complements, a fixed subsidy will be sufficient to jump-start a multi-firm industry if the degree of complementarity between the two goods is high. Otherwise, it will be necessary to augment the fixed subsidy with an additional variable subsidy.

Two scenarios are possible for the case of substitutes; firm $B$ enters only if firm $A$ 's period-1 output is sufficiently high (part (b-i) of the Proposition), or firm $B$ enters only if firms A's period-1 output is sufficiently low (part (b-ii) of the Proposition). In the first case, a relatively large share of the learning is external so that firm $B$ 's entry occurs only if $Q_{A}^{1}$ is sufficiently large. The government intervention can be successful in this case if it offers a sufficiently high per-unit subsidy. ${ }^{12}$ The duopoly outcome is more attractive to firm $A$ in this case because firm $A$ would have to restrict its period-1 output by a relatively large amount to deter entry of firm $B$ and, as a result, would forego a relatively large payment associated with the per-unit subsidy. In the second case, the government will prevent too much production in period 1 by introducing a per-unit tax. To induce entry by firm $A$ in period 1 the government needs to offset the per-unit tax by a sufficiently large lump-sum subsidy and a requirement that the pioneer firm needs to produce period-1 output above some strictly positive level in order to qualify for the lump-sum subsidy.

\section{Discussion and Conclusion}

The paper examines coordination and learning market failures that can block development of an otherwise-profitable industry, and the mechanism by which upfront subsidies could potentially offset the market failures and jump-start the development of a multi-firm industry. The concept of the jump-start strategy is appealing: if entry is blocked by coordination failures or learning externalities, the jump-start strategy offers the possibility that the government may be able to create a new industry by subsidizing an initial entrant - without conferring long-term market power on that firm. Instead, the coordination and learning externalities created by the subsidized firm may induce entry by suppliers and customers, to produce the infrastructure needed to support production of the new good. Development of this infrastructure may induce subsequent entry by firms that will compete with the subsidized firm, thereby reducing the

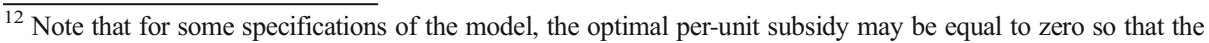
government may jump-start a multi-firm industry by using only a fixed subsidy.
} 
pioneer's market power. The possibility that the pioneer's market power will be short-lived is particularly enticing when a government is considering jump-starting an industry that will produce a merit good for domestic consumption. Similarly, the coordination externalities created by the subsidized firm may induce entry by suppliers.

Our results indicate, however, that this strategy should be viewed with caution. A onetime fixed subsidy that induces entry by the pioneer firm will not generally be sufficient to jump-start a multi-firm industry. Augmenting the period-one fixed subsidy with a period-one per-unit subsidy can induce entry by the pioneer firm and a second entrant, if the two firms will produce complementary goods. This two-part subsidy strategy can effectively induce subsequent competitive entry when a large share of the learning is external. When the firms produce substitutes and a large share of the learning is internal, the government the jump-start strategy may require offering a sufficiently large per-unit tax and offsetting it by a sufficiently large lump-sum subsidy.

These results provide a basis for considering whether the jump-start strategy can be expected to address the potential that the pioneer firm may enjoy lasting market power. While this issue does not have first-order importance in models that focus on the development of export industries, it is salient when the new industry will produce merit goods for the domestic economy. This problem has not been addressed in the models that focus on the development of export industries, because the consumers who will pay the monopoly prices are not located in the home country. However, this issue is salient when the new industry will produce merit goods for the domestic economy.

\section{Appendix}

Proof of Lemma 1: Totally differentiating the equations in (2), we obtain:

$$
\begin{aligned}
\frac{d \hat{Q}_{A}^{2}}{d Q_{A}^{1}}= & \frac{\frac{\partial^{2} c_{A}^{2}\left(\hat{Q}_{A}^{2}, Q_{A}^{1}\right)}{\partial Q_{A}^{2} \partial Q_{A}^{1}}\left(\frac{\partial^{2} R_{B}\left(\hat{Q}_{B}^{2}, \hat{Q}_{A}^{2}\right)}{\partial\left(Q_{B}^{2}\right)^{2}}-\frac{\partial^{2} c_{B}\left(\hat{Q}_{B}^{2}, Q_{A}^{1}\right)}{\partial\left(Q_{B}^{2}\right)^{2}}\right)-\frac{\partial^{2} R_{A}\left(\hat{Q}_{A}^{2}, \hat{Q}_{B}^{2}\right)}{\partial Q_{A}^{2} \partial Q_{B}^{2}} \frac{\partial^{2} c_{B}\left(\hat{Q}_{B}^{2}, Q_{A}^{1}\right)}{\partial Q_{B}^{2} \partial Q_{A}^{1}}}{M}, \\
\frac{d \hat{Q}_{B}^{2}}{d Q_{A}^{1}}= & \frac{\partial^{2} c_{B}^{2}\left(\hat{Q}_{A}^{2}, Q_{A}^{1}\right)}{\partial Q_{B}^{2} \partial Q_{A}^{1}}\left(\frac{\partial^{2} R_{A}\left(\hat{Q}_{A}^{2}, \hat{Q}_{B}^{2}\right)}{\partial\left(Q_{A}^{2}\right)^{2}}-\frac{\partial^{2} c_{A}^{2}\left(\hat{Q}_{A}^{2}, Q_{A}^{1}\right)}{\partial\left(Q_{A}^{2}\right)^{2}}\right)-\frac{\partial^{2} R_{B}\left(\hat{Q}_{A}^{2}, \hat{Q}_{B}^{2}\right)}{\partial Q_{B}^{2} \partial Q_{A}^{2}} \frac{\partial^{2} c_{A}^{2}\left(\hat{Q}_{A}^{2}, Q_{A}^{1}\right)}{\partial Q_{A}^{2} \partial Q_{A}^{1}}
\end{aligned}
$$

where $M \equiv\left(\frac{\partial^{2} R_{B}\left(\hat{Q}_{B}^{2}, \hat{Q}_{A}^{2}\right)}{\partial\left(Q_{B}^{2}\right)^{2}}-\frac{\partial^{2} c_{B}\left(\hat{Q}_{B}^{2}, Q_{A}^{1}\right)}{\partial\left(Q_{B}^{2}\right)^{2}}\right)\left(\frac{\partial^{2} R_{A}\left(\hat{Q}_{A}^{2}, \hat{Q}_{B}^{2}\right)}{\partial\left(Q_{A}^{2}\right)^{2}}-\frac{\partial^{2} c_{A}^{2}\left(\hat{Q}_{A}^{2}, Q_{A}^{1}\right)}{\partial\left(Q_{A}^{2}\right)^{2}}\right)-\frac{\partial^{2} R_{A}\left(\hat{Q}_{A}^{2}, \hat{Q}_{B}^{2}\right)}{\partial Q_{A}^{2} \partial Q_{B}^{2}} \frac{\partial^{2} R_{B}\left(\hat{Q}_{A}^{2}, \hat{Q}_{B}^{2}\right)}{\partial Q_{B}^{2} \partial Q_{A}^{2}}$.

Note that $M>0$ by the stability condition which was assumed to hold.

First, consider the case of complementary goods (case (a) in Lemma 1). Using $\frac{\partial^{2} c_{A}^{2}}{\partial Q_{A}^{2} \partial Q_{A}^{1}}$, $\frac{\partial^{2} c_{B}}{\partial Q_{B}^{2} \partial Q_{A}^{1}}, \frac{\partial^{2} R_{B}}{\partial\left(Q_{B}^{2}\right)^{2}}-\frac{\partial^{2} c_{B}}{\partial\left(Q_{B}^{2}\right)^{2}}, \frac{\partial^{2} R_{A}}{\partial\left(Q_{A}^{2}\right)^{2}}-\frac{\partial^{2} c_{A}^{2}}{\partial\left(Q_{A}^{2}\right)^{2}},-M,-\frac{\partial^{2} R_{A}}{\partial Q_{A}^{2} \partial Q_{B}^{2}}, \frac{\partial^{2} R_{B}}{\partial Q_{B}^{2} \partial Q_{A}^{2}} \leq 0$ and (A1) we obtain that $\frac{d \hat{Q}_{A}^{2}}{d Q_{A}^{1}}, \frac{d \hat{Q}_{B}^{2}}{d Q_{A}^{1}} \geq 0$. Proof of case (b) follows directly from (A1) and $M>0$. QED 
Proof of Lemma 3: Differentiating (10) and (11) and using the first-order conditions for the choice in period 2 we obtain implicit expressions for $\hat{Q}_{A}^{1}$ and $\bar{Q}_{A}^{1}$, respectively:

$$
\begin{aligned}
& \frac{\partial \pi^{D}\left(\hat{Q}_{A}^{1} ; v, S\right)}{\partial Q_{A}^{1}} \equiv \frac{\partial R_{A}\left(\hat{Q}_{A}^{1}, 0\right)}{\partial Q_{A}^{1}}+v-\frac{\partial c_{A}^{1}\left(\hat{Q}_{A}^{1}\right)}{\partial Q_{A}^{1}} \\
& +\frac{\partial R_{A}\left(\hat{Q}_{A}^{2}\left(\hat{Q}_{A}^{1}\right), \hat{Q}_{B}^{2}\left(\hat{Q}_{A}^{1}\right)\right)}{\partial Q_{B}^{2}} \frac{\partial \hat{Q}_{B}^{2}\left(\hat{Q}_{A}^{1}\right)}{\partial Q_{A}^{1}}-\frac{\partial c_{A}^{2}\left(\hat{Q}_{A}^{2}\left(\hat{Q}_{A}^{1}\right), \hat{Q}_{A}^{1}\right)}{\partial Q_{A}^{1}} \\
& \quad=0
\end{aligned}
$$

$$
\frac{\partial \pi^{M}\left(\bar{Q}_{A}^{1} ; v, S\right)}{\partial Q_{A}^{1}} \equiv \frac{\partial R_{A}\left(\bar{Q}_{A}^{1}, 0\right)}{\partial Q_{A}^{1}}+v-\frac{\partial c_{A}^{1}\left(\bar{Q}_{A}^{1}\right)}{\partial Q_{A}^{1}}-\frac{\partial c_{A}^{2}\left(\bar{Q}_{A}^{2}\left(\bar{Q}_{A}^{1}\right), \bar{Q}_{A}^{1}\right)}{\partial Q_{A}^{1}}=0 .
$$

Evaluating the derivative of $\partial \pi^{D}\left(Q_{A}^{1} ; v, S\right)$ at $\bar{Q}_{A}^{1}$ and using (A2) we obtain:

$$
\begin{aligned}
\frac{\partial \pi^{D}\left(\bar{Q}_{A}^{1} ; v, S\right)}{\partial Q_{A}^{1}}= & \frac{\partial c_{A}^{2}\left(\bar{Q}_{A}^{2}\left(\bar{Q}_{A}^{1}\right), \bar{Q}_{A}^{1}\right)}{\partial Q_{A}^{1}}-\frac{\partial c_{A}^{2}\left(\hat{Q}_{A}^{2}\left(\bar{Q}_{A}^{1}\right), \bar{Q}_{A}^{1}\right)}{\partial Q_{A}^{1}} \\
& +\frac{\partial R_{A}\left(\hat{Q}_{A}^{2}\left(\bar{Q}_{A}^{1}\right), \hat{Q}_{B}^{2}\left(\bar{Q}_{A}^{1}\right)\right)}{\partial Q_{B}^{2}} \frac{\partial \hat{Q}_{B}^{2}\left(\bar{Q}_{A}^{1}\right)}{\partial Q_{A}^{1}} .
\end{aligned}
$$

First, consider the case of complementary goods. The inequality $\bar{Q}_{A}^{2}\left(\bar{Q}_{A}^{1}\right) \leq \hat{Q}_{A}^{2}\left(\bar{Q}_{A}^{1}\right)$ and convexity of $c_{A}^{2}$ in its first argument imply that $\partial c_{A}^{2}\left(\bar{Q}_{A}^{2}\left(\bar{Q}_{A}^{1}\right) \frac{\left.\bar{Q}_{A}^{1}\right)}{\partial Q_{A}^{1}-\partial c_{A}^{2}\left(\hat{Q}_{A}^{2}\left(\bar{Q}_{A}^{1}\right)\right.} \frac{\left.\bar{Q}_{A}^{1}\right)}{\partial Q_{A}^{1} \geq 0}\right.$. Furthermore, $\partial R_{A}\left(\hat{Q}_{A}^{2}\left(\bar{Q}_{A}^{1}\right) \frac{\left.\hat{Q}_{B}^{2}\left(\bar{Q}_{A}^{1}\right)\right)}{\partial Q_{B}^{2} \geq 0}\right.$. Combined with the result from Lemma 1, that $\frac{\partial \hat{Q}_{B}^{2}\left(\bar{Q}_{A}^{1}\right)}{\partial Q_{A}^{1}} \geq 0$ for the case of complements, this implies that $\frac{\partial \pi^{M}\left(\bar{Q}_{A}^{1} ;, s\right)}{\partial Q_{A}^{1}} \geq 0$. Hence, $\bar{Q}_{A}^{1} \leq \hat{Q}_{A}^{1}$.

Suppose now that firms $A$ and $B$ produce substitute goods. The inequality $\bar{Q}_{A}^{2}\left(\bar{Q}_{A}^{1}\right) \geq \hat{Q}_{A}^{2}$ $\left(\bar{Q}_{A}^{1}\right)$ implies that $\partial c_{A}^{2}\left(\bar{Q}_{A}^{2}\left(\bar{Q}_{A}^{1}\right) \frac{\left.\bar{Q}_{A}^{1}\right)}{\partial Q_{A}^{1}-\partial c_{A}^{2}\left(\hat{Q}_{A}^{2}\left(\bar{Q}_{A}^{1}\right)\right.} \frac{\left.\bar{Q}_{A}^{1}\right)}{\partial Q_{A}^{1} \leq 0}\right.$. Furthermore, $\partial R_{A}\left(\hat{Q}_{A}^{2}\left(\bar{Q}_{A}^{1}\right) \frac{\left.\hat{Q}_{B}^{2}\left(\bar{Q}_{A}^{1}\right)\right)}{\partial Q_{B}^{2} \leq 0}\right.$. Hence, if $\frac{\partial \hat{Q}_{B}^{2}\left(\bar{Q}_{A}^{1}\right)}{\partial Q_{A}^{\perp}} \geq 0$, then $\frac{\partial \pi^{D}\left(\bar{Q}_{A}^{1} ; v, S\right)}{\partial Q_{A}^{1}}$ is unambiguously negative, which implies $\bar{Q}_{A}^{1} \geq \hat{Q}_{A}^{1}$. However, when $\frac{\partial \hat{Q}_{B}^{2}\left(\bar{Q}_{A}^{1}\right)}{\partial Q_{A}^{1}} \leq 0, \frac{\partial \pi^{D}\left(\bar{Q}_{A}^{1} ;, S\right)}{\partial Q_{A}^{1}}$ has an ambiguous sign. QED

Open Access This article is distributed under the terms of the Creative Commons Attribution 4.0 International License (http://creativecommons.org/licenses/by/4.0/), which permits unrestricted use, distribution, and reproduction in any medium, provided you give appropriate credit to the original author(s) and the source, provide a link to the Creative Commons license, and indicate if changes were made. 


\section{References}

Blumenthal D (2006) Health information technology: What is the federal government's role? Commonwealth Fund/Alliance for Health Reform 2006 Bipartisan Congressional Health Policy Conference: 1-16

Bulow J, Geanakoplos J, Klemperer P (1985) Multimarket oligopoly: strategic substitutes and complements. J Polit Econ 93:488-511

Dearlove D (2001) The cluster effect: can Europe clone silicon valley?. Strategy + Business Third Quarter 2001. Issue 24

Eagle SJ (2009) Kelo, directed growth and municipal industrial policy. Supreme Court Econ Rev 17(1):63-126

Fudenberg D, Tirole J (1984) The fat-cat effect, the puppy-dog ploy, and the lean and hungry look. Am Econ Rev 74(2):361-366, Papers and Proceedings

Fudenberg D, Tirole J (1986) Dynamic models of oligopoly. Harwood, London

Fudenberg D, Tirole J (1991) Game theory. MIT Press

Grossman GM (1989) Promoting New industrial activities: a survey of recent arguments and evidence. Woodrow Wilson School of Public and International Affairs Paper \# 147, Princeton University

Kelly, E., 2010. Harry Reid ranks sixth in Senate in 2010 for earmarks. Gannett News Service. Reno Gazette Journal. August 1, 2010, page 1.

Krugman P (1987) The narrow moving band, the Dutch disease, and the competitive consequences of Mrs. Thatcher: notes on trade in the presence of dynamic scale economies. J Dev Econ 27(1-2):41-55

Milgrom P, Roberts J (1990) Rationalizability, learning, and equilibrium in games with strategic complementarities. Econometrica 58:1255-1278

Neary JP, Leahy D (2000) Strategic trade and industrial policy towards dynamic oligopolies. Econ J 110:484-508

Pack H, Saggi K (2006) Is there a case for industrial policy? a critical survey. World Bank Res Observer 21(2): 267-297

Pflüger M, Südekum J (2013) Subsidizing firm entry in open economies. J Public Econ 97:258-271

America Reinvestment and Recovery Act (2009) www.recovery.gov and http://www.afdc.energy. gov/afdc/laws/key_legislation\#recovery

Rodriguez-Clare A (2007) Clusters and comparative advantage: implications for industrial policy. J Dev Econ 82: 43-57

Romero-Martínez AM, Montoro-Sánchez A (2008) How clusters can encourage entrepreneurship and venture creation. reasons and advantages. Int Entrep Manag J 4:315-329

Topkis DM (1979) Equilibrium points in non-zero sum n-person submodular games. SIAM Jo Contrl Optimiz 17(6):773-787

Topkis DM (1998) Submodularity and complementarity. Princeton University Press, Princeton

Vives X (1990) Nash equilibrium with strategic complementrities. J Math Econ 19:305-321

Wills JB (2014) Government clean air regulations and Tesla motors. San Jose State University 